\title{
Natalizumab promotes activation and pro- inflammatory differentiation of peripheral $B$ cells in multiple sclerosis patients
}

\author{
Jan W. Traub ${ }^{1,2}$, Hannah L. Pellkofer ${ }^{2,3}$, Katja Grondey ${ }^{1}$, Ira Seeger ${ }^{1}$, Christoph Rowold ${ }^{1,2}$, Wolfgang Brück', \\ Leila Husseini ${ }^{2}$, Silke Häusser-Kinzel ${ }^{1}$ and Martin S. Weber ${ }^{1,2^{*}}$ (i)
}

\begin{abstract}
Background: In the past, multiple sclerosis (MS) medications have been primarily designed to modulate T cell properties. Based on the emerging concept that B cells are equally important for the propagation of MS, we compared the effect of four commonly used, primarily T cell-targeting MS medications on B cells.

Methods: Using flow cytometry, we analyzed peripheral blood mononuclear cells (PBMC) of untreated $(n=19)$ and dimethyl fumarate (DMF; $n=21)$-, fingolimod (FTY; $n=17)$-, glatiramer acetate (GA; $n=18)$ ), and natalizumab (NAT; $n=20$ )-treated MS patients, focusing on B cell maturation, differentiation, and cytokine production.

Results: While GA exerted minor effects on the investigated B cell properties, DMF and FTY robustly inhibited pro-inflammatory B cell function. In contrast, NAT treatment enhanced B cell differentiation, activation, and pro-inflammatory cytokine production when compared to both intraindividual samples collected before NAT treatment initiation as well as untreated MS controls. Our mechanistic in vitro studies confirm this observation.

Conclusion: Our data indicate that common MS medications have differential, in part opposing effects on B cells. The observed activation of peripheral B cells upon NAT treatment may be instructive to interpret its unfavorable effect in certain B cell-mediated inflammatory conditions and to elucidate the immunological basis of MS relapses after NAT withdrawal.
\end{abstract}

Trial registration: Protocols were approved by the ethical review committee of the University Medical Center Göttingen (\#3/4/14).

Keywords: Multiple sclerosis, Natalizumab, B cells, Dimethyl fumarate, Glatiramer acetate, Fingolimod

\section{Background}

The enormous success of B cell-depleting anti-CD20 antibodies in treatment of multiple sclerosis (MS) [1] corroborates that $\mathrm{B}$ cells play an important role in its pathogenesis. Antigen-activated, differentiated B cells most likely act as potent antigen-presenting cells for the activation of $\mathrm{T}$ cells and as providers of pro-inflammatory cytokines [2]. Hereby, B cells are considered to be crucial for the

\footnotetext{
* Correspondence: martin.weber@med.uni-goettingen.de

'Institute of Neuropathology, University Medical Center, Robert-Koch-Straße 40, 37099 Göttingen, Germany

${ }^{2}$ Department of Neurology, University Medical Center, Robert-Koch-Straße 40, 37099 Göttingen, Germany

Full list of author information is available at the end of the article
}

development of new inflammatory central nervous system (CNS) lesions and acute MS relapses.

Based on the earlier assumption that the pathophysiology of MS is mainly mediated by T cells, the majority of established MS medications have been designed and trialed to target pro-inflammatory $\mathrm{T}$ cell properties. As a consequence, relatively little is known on how these MS drugs may influence B cells, and if so, how this may contribute to their therapeutic efficacy. Therefore, we investigated in a parallel approach how the four commonly prescribed medications dimethyl fumarate (DMF), fingolimod (FTY), glatiramer acetate (GA), and natalizumab (NAT) affect peripheral $B$ cells with a focus on B cell activation, differentiation, and cytokine production, a procedure allowing us to directly compare treatment effects without inter-study discrepancies. 


\section{Methods}

\section{Study subjects and sample preparation}

We collected peripheral blood from relapsing-remitting MS patients at the Clinical MS Center of the University Medical Center Göttingen (\#3/4/14) between 2015 and 2018. Patients had received DMF, FTY, GA, and NAT according to the current European guidelines [3] for the respective drug for at least 6 months or had not received any permanent medication or steroids for at least 6 months (untreated controls). Seven patients receiving NAT were in addition analyzed longitudinally. Demographic and disease-related information including age, gender, disease activity, disease onset, treatment duration, and previous treatments of the patient cohorts are summarized in Table 1. Human peripheral blood mononuclear cells (PBMC) were isolated by Ficoll density gradient centrifugation. Samples were cryopreserved in Dulbecco's modified Eagle medium (DMEM; Sigma Aldrich, MO) containing 20\% dimethyl sulfoxide (Sigma Aldrich, MO) and 20\% fetal calf serum (FCS, Sigma Aldrich, MO) and stored at $-80{ }^{\circ} \mathrm{C}$.

\section{Cell count determination}

Immune cell counts from whole blood were determined in our hospital's routine laboratory. To determine the frequency of the respective immune cell populations $\left(\mathrm{CD} 4^{+}, \mathrm{CD}^{+}\right.$, and $\mathrm{CD} 19^{+}$cells), we first excluded doublets, followed by gating for lymphocytes according to their size and granularity (FSC vs SSC). Thereafter, we gated for living lymphocytes by exclusion of Zombie positive cells, finally determining the frequency of $\mathrm{CD} 4^{+}$, $\mathrm{CD}^{+}$, and $\mathrm{CD} 19^{+}$within all living lymphocytes. We then multiplied the lymphocyte count with the fraction of the lymphocyte subset of interest determined by flow cytometry. Since this approach is based on scatter gating only, there is some room for small inaccuracies which should be considered when evaluating the data.

\section{PBMC handling and stimulation}

For analysis, cells were thawed; washed in DMEM containing 10\% FCS, 1\% sodium pyruvate (Sigma Aldrich, $\mathrm{MO}$ ), $1 \%$ L-glutamine (Sigma Aldrich, MO), and 0.1\% $\beta$ mercaptoethanol (Sigma Aldrich, MO); and plated at a concentration of $0.5 \times 10^{6}$ cells $/ \mathrm{ml}$ in 96-well U-bottom plates (Sarstedt, Germany). For the analysis of activation marker and co-stimulatory molecules, PBMC were stimulated with $2 \mu \mathrm{g} / \mathrm{ml} \mathrm{CpG} \mathrm{oligodeoxynucleotides} \mathrm{(CpG)}$ or $100 \mathrm{pg} / \mathrm{ml}$ lipopolysaccharide (LPS) as indicated for $20 \mathrm{~h}$ at $37^{\circ} \mathrm{C}$ and $5 \% \mathrm{CO}_{2}$.

To determine the intracellular cytokine content, PBMC were cultured for $12 \mathrm{~h}$ in the presence of $1 \mu \mathrm{g} / \mathrm{ml}$ CpG followed by incubation with $500 \mathrm{ng} / \mathrm{ml}$ ionomycin, $20 \mathrm{ng} / \mathrm{ml}$ phorbol 12-myristate 13-acetate (PMA; both Sigma Aldrich, MO), and the protein transport inhibitor GolgiPlug (BD Bioscience, NJ) for $4 \mathrm{~h}$ according to the manufacturer's recommendations. For the in vitro analysis of NAT-mediated effects, we incubated PBMC of healthy donors for $4 \mathrm{~h}$ with various concentrations of NAT or an immunoglobulin G (IgG) 4 isotype control antibody (IGHG4; Biolegend, CA) followed by $40 \mathrm{~h}$ simultaneous incubation with NAT/control and $1 \mu \mathrm{g} / \mathrm{ml}$ CpG. Thereafter, GolgiPlug, $500 \mathrm{ng} / \mathrm{ml}$ ionomycin, and $20 \mathrm{ng} / \mathrm{ml}$ PMA were added for additional $6 \mathrm{~h}$. Geometric mean fluorescent intensity (gMFI) of intracellularly accumulated cytokines was determined via flow cytometry.

Table 1 Characteristics of the patient cohorts

\begin{tabular}{|c|c|c|c|c|c|c|}
\hline & Control & DMF & FTY & GA & NAT & NAT longitudinal \\
\hline Number of patients & 19 & 21 & 17 & 18 & 20 & 7 \\
\hline Age (y) & $34.2 \pm 8.1$ & $37.0 \pm 11.9$ & $39.5 \pm 9.4$ & $40.1 \pm 9.1$ & $35.7 \pm 10.3$ & $25.6 \pm 6.3$ \\
\hline Female sex (\%) & 73.7 & 47.6 & 64.7 & 50.0 & 55.0 & 71.4 \\
\hline EDSS score & $2.00 \pm 1.40$ & $1.95 \pm 1.50$ & $2.76 \pm 1.39$ & $1.81 \pm 1.43$ & $3.70 \pm 2.11$ & $2.64 \pm 2.01$ \\
\hline MS since $(y)$ & $5.07 \pm 5.30$ & $5.48 \pm 3.89$ & $12.00 \pm 4.50$ & $7.50 \pm 4.04$ & $9.50 \pm 5.45$ & $2.39 \pm 2.81$ \\
\hline Drug taken since $(y)$ & - & $0.73 \pm 0.31$ & $1.75 \pm 0.99$ & $4.22 \pm 2.48$ & $3.57 \pm 2.78$ & - \\
\hline \multicolumn{7}{|l|}{ Previous treatment $(n)$} \\
\hline Interferon beta & 0 & 5 & 3 & 1 & 10 & 1 \\
\hline Glatiramer acetate & 0 & 3 & 2 & 0 & 2 & 1 \\
\hline Natalizumab & 0 & 2 & 4 & 0 & 0 & 0 \\
\hline Fingolimod & 0 & 0 & 0 & 0 & 2 & 0 \\
\hline Mitoxantrone & 0 & 0 & 0 & 0 & 0 & 1 \\
\hline None & 19 & 11 & 8 & 17 & 6 & 4 \\
\hline
\end{tabular}

Control multiple sclerosis (MS) patients had not been treated with any immunomodulatory drug for at least 6 months when phlebotomy was performed, while dimethyl fumarate (DMF)-, fingolimod (FTY)-, glatiramer acetate (GA)-, and natalizumab (NAT)-treated MS patients were on medication for at least 6 months before sampling. Data are displayed as mean \pm standard deviation

EDSS Expanded Disability Status Scale, $y$ years 


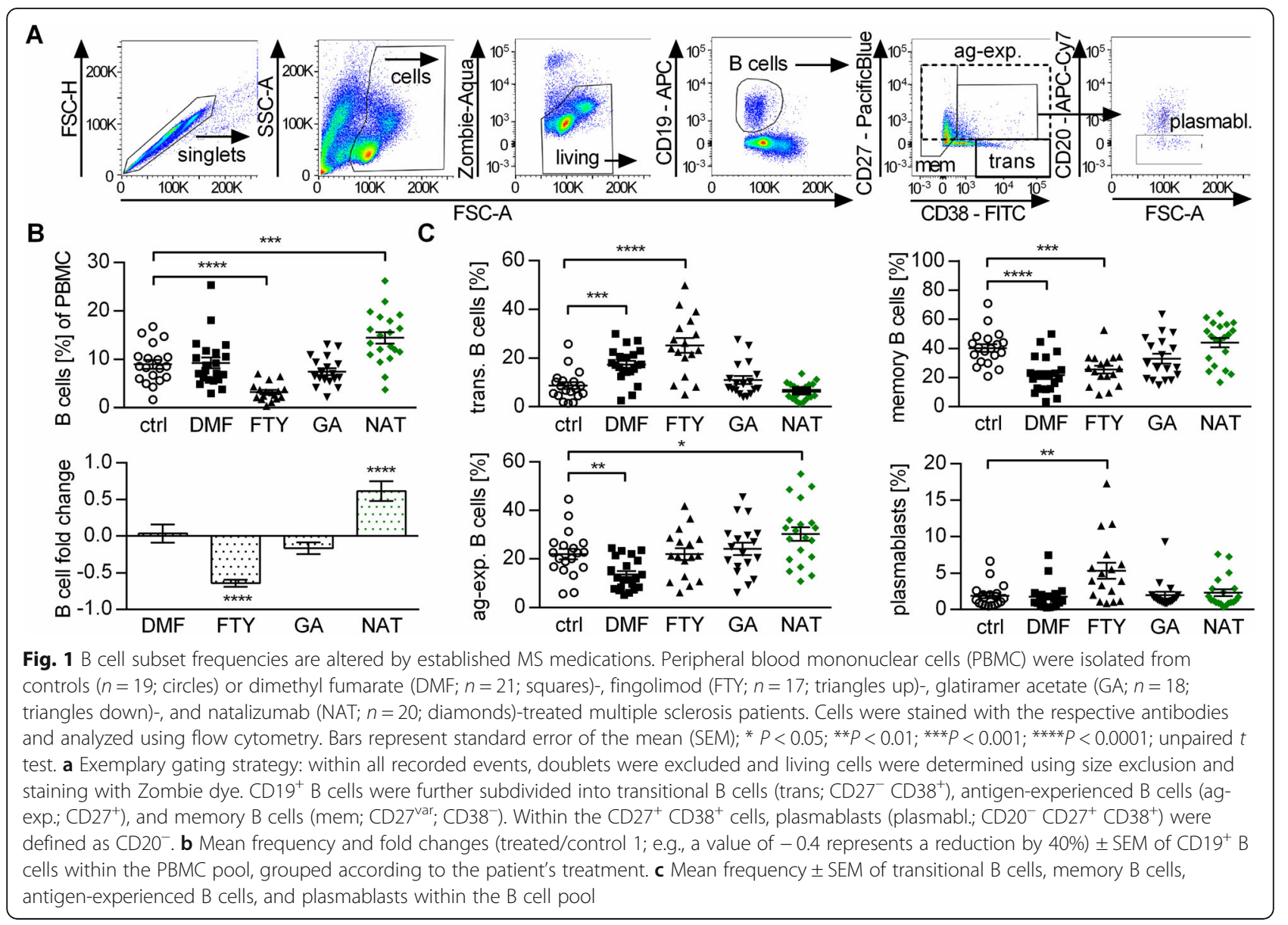

For the evaluation of apoptosis, PBMC were incubated with $30 \mu \mathrm{g} / \mathrm{ml}$ NAT or isotype control antibody for $72 \mathrm{~h}$.

\section{Flow cytometry analysis}

Prior to antibody incubation, cells were stained with viability dye (Zombie ${ }^{\mathrm{Tw}}$ dye, 1:500, Biolegend) for live cell/ dead cell discrimination and incubated with Fc receptor blocking solution (Human TruStain FcX, BioLegend, CA) to prevent unspecific antibody binding. Extracellular antigens were stained using anti-human cluster of differentiation (CD)4-PE-Cy7, CD8-PE, CD14-PE-CF594 and CD19-FITC/PerCP-Cy5.5, CD20-APC-Cy7, CD25-BV605, CD27-PacificBlue, CD38-FITC, CD80-PE-Cy7, CD150BV-421, major histocompatibility complex class II (MHC-II)-APC (all Biolegend, CA), CD19-PerCp-Cy5.5, CD40-PE-Dazzle, CD69-FITC, CD86-BV421, and CD95$\mathrm{PE}$ (all BD Biosciences, NJ) antibodies. For analysis of intracellular cytokines, cells were permeabilized by adding fixation/permeabilization solution (Cytofix/Cytoperm, BD Biosciences, NJ) and stained with anti-human interleukin (IL)-6-FITC, IL-10-PE/CF594, and tumor necrosis factor (TNF)-Alexa Flour 700 (all BD Biosciences, NJ) antibodies. Apoptosis was evaluated using propidium iodide-PE and annexin V-FITC (both BioLegend, CA).
Samples were analyzed using a LSRII Fortessa; FACS Diva (BD Biosciences) and FlowJo software were used to quantify flow cytometric data.

\section{$B$ cell proliferation assay}

For the analysis of B cell proliferation, B cells were isolated using magnetic-activated cell sorting (MACS; anti-human CD19 MicroBeads, Miltenyi Biotec). After carboxyfluorescein succinimidyl ester (CFSE) staining (BD Biosciences), 60,000 cells/well were plated in 96-well plates and stimulated with anti-human IgG and IgM $\mathrm{F}(\mathrm{ab})_{2}$ antibody fragments $(20 \mu \mathrm{g} / \mathrm{ml}$; Jackson Immunoreaearch, PA), anti-human CD40 antibodies $(10 \mu \mathrm{g} / \mathrm{ml}$; BioCell, NH), CpG $(0.5 \mu \mathrm{g} / \mathrm{ml})$, and IL21 $(50 \mathrm{ng} / \mathrm{ml})$ for $72 \mathrm{~h}$. Samples were analyzed using a LSRII Fortessa; FACS Diva (BD Biosciences) and FlowJo software were used to quantify flow cytometric data.

\section{Statistical analysis}

For normality testing, we used the D'Agostino \& Pearson omnibus normality test; the paired $t$ test was used for parametric data, Mann-Whitney $U$ tests for non-parametric data, and the Wilcoxon signed-rank tests for longitudinal samples. Statistical significance was defined as $P<0.05$. 


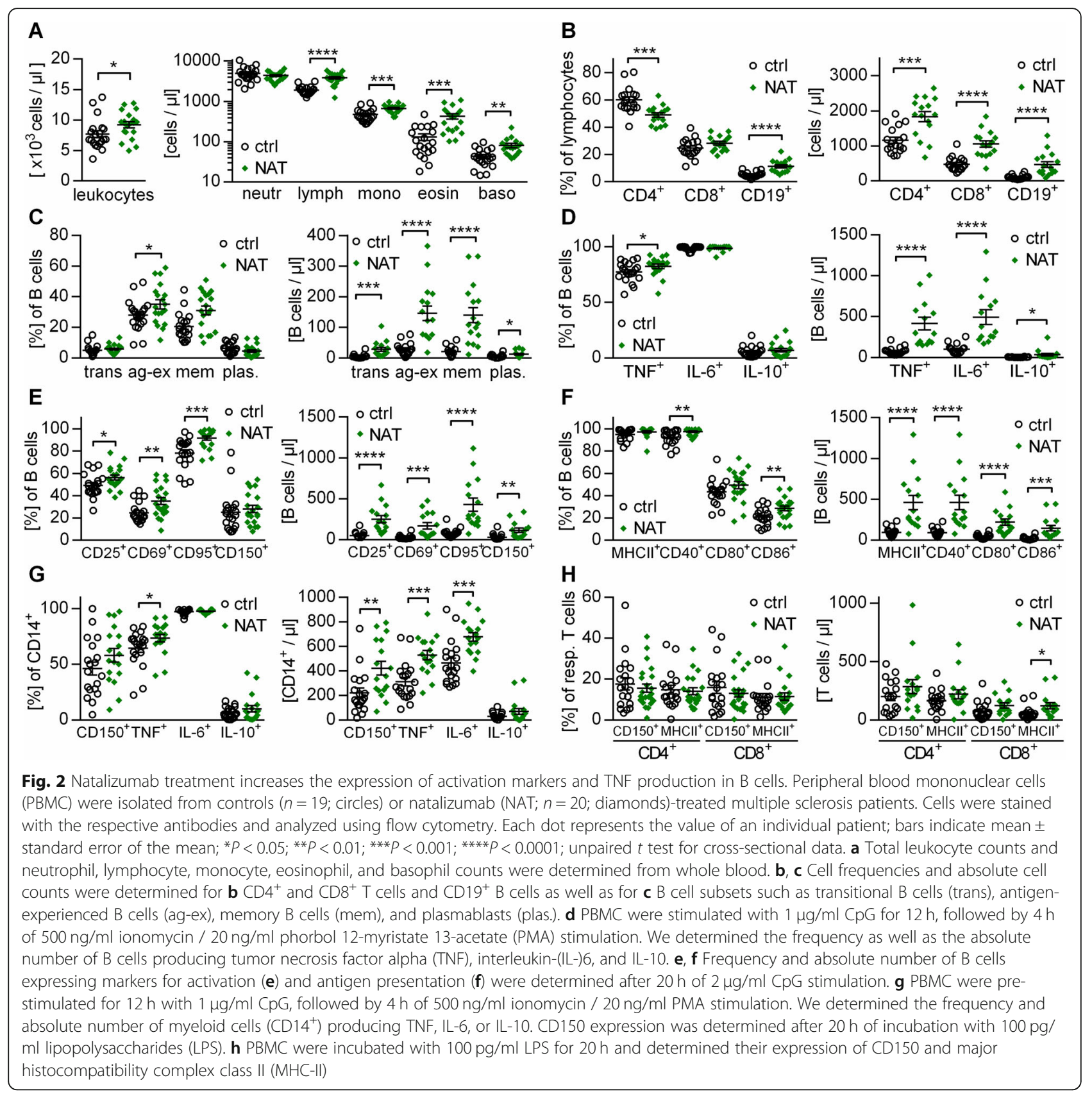

\section{Results}

First, we investigated the effect of treatment with FTY, NAT, DMF, and GA on the overall abundance of B cells in the blood. Compared to untreated MS patients, the FTY group showed a reduced B cell frequency, NAT treatment resulted in a significant increase of B cells, and both DMF and GA had no detectable effect (Fig. 1a, b). DMF and even more so FTY raised the relative abundance of immature transitional B cells, while the frequency of differentiated memory B cells was correspondingly lower in both groups. DMF treatment was furthermore associated with a reduced frequency of $\mathrm{CD} 27^{+}$antigenexperienced B cells, while NAT treatment resulted in a substantial rise of this mature B cell population. Lastly, the proportion of plasmablasts was elevated upon FTY treatment (Fig. 1c). Using this set of parameters, GA treatment exerted no detectable effect on B cells.

Analyzing the effect of NAT in detail, we found that NAT treatment was associated with an incline of the total number of leukocytes (Fig. 2a left), including 
lymphocytes, monocytes, eosinophils, and basophils (Fig. 2a right). Within the enriched fraction of lymphocytes, the frequency of $\mathrm{B}$ cells was proportionally increased, while $\mathrm{CD} 4^{+} \mathrm{T}$ cells were compensatory reduced (Fig. 2b left). However, when calculating absolute numbers, all investigated immune cell populations were significantly elevated upon NAT treatment (Fig. 2b right). Furthermore, B cells from NAT-treated patients were distinctly enriched in antigen-activated and memory B cells (Fig. 2c), showed a higher production of pro-inflammatory cytokines (Fig. 2d), and presented with an elevated frequency and total number of activated $\mathrm{CD} 25^{+}, \mathrm{CD} 69^{+}$, and $\mathrm{CD}^{+} 5^{+}$cells (Fig. 2e). While the expression of MHC-II remained unchanged, the level of the co-stimulatory molecules CD40, CD80, and CD86 was increased on B cells upon NAT treatment (Fig. 2f). In conjunction, this finding revealed a rise in all investigated immune cell subpopulations and pointed towards a predominant increase in proinflammatory B cell subsets upon NAT treatment. In line with this data, the longitudinal analysis of interrelated samples collected prior and after NAT treatment initiation confirmed our observations regarding memory, antigenexperienced $\left(\mathrm{CD} 27^{+}\right), \mathrm{CD}_{4} 0^{+}, \mathrm{CD}^{+} 5^{+}$, and $\mathrm{TNF}^{+} \mathrm{B}$ cells (Fig. 3) and consolidated the assumption that NAT treatment triggers the activation and pro-inflammatory differentiation of B cells. In addition, NAT treatment was associated with an increase in the production of proinflammatory TNF and IL- 6 by $\mathrm{CD}^{+} 4^{+}$myeloid cells (Fig. 2g) as well as an enhanced expression of the activation marker CD150, an effect which was even more pronounced when absolute cell numbers were analyzed. Only minor effects could be detected regarding the assessed parameters on $\mathrm{T}$ cells, where the number of $\mathrm{MHC}-\mathrm{II}^{+} \mathrm{CD} 8^{+}$ $\mathrm{T}$ cells was slightly elevated in NAT-treated patients (Fig. $2 \mathrm{~h})$.

In order to study the immune-stimulating effect of NAT mechanistically, we cultured whole PBMC of healthy donors with increasing concentrations of NAT $(0-120 \mu \mathrm{g} / \mathrm{ml})$ in vitro, which were chosen according to reported serum levels in treated patients [4]. In line with the patient's ex vivo data, in vitro NAT exposure enhanced the production of proinflammatory TNF and IL- 6 by $\mathrm{B}$ cells and CD14 ${ }^{+}$ myeloid cells (Fig. 4a, b) and upregulated the expression of CD40, CD69, and CD95 on B cells (Fig. 4c). To explain mechanistically how the aforementioned enrichment of B cells in NAT-treated patients may occur, we investigated the proliferation and apoptosis behavior of these cells upon NAT treatment. Within the chosen culture period, NAT exposure to PBMC or purified B cells exerted an effect on neither B cell frequency (no antibody $11.1 \pm 0.7 \%$, NAT $12.0 \pm 0.9 \%$; isotype $11.8 \pm 1.1 \%$ ), nor their apoptosis rate (Fig. 5a, b) or proliferation (Fig. 5 c-d).

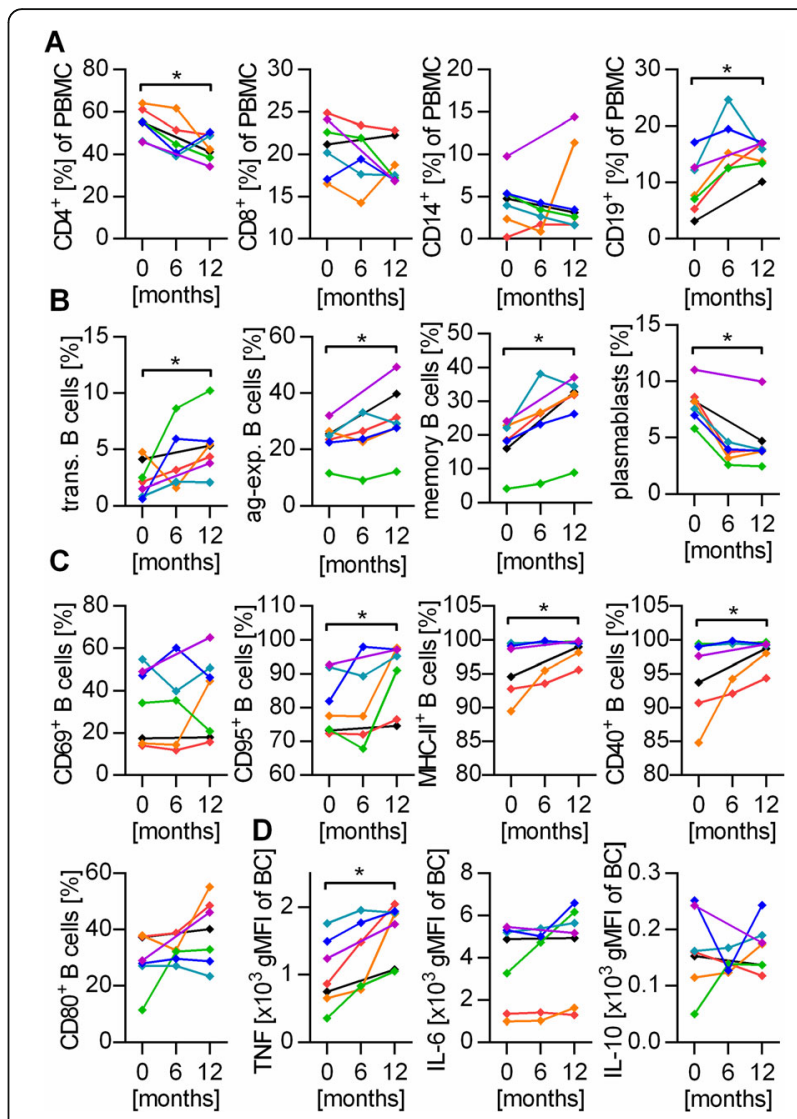

Fig. 3 Natalizumab increases pro-inflammatory properties of B cells in longitudinal samples. Blood samples $(n=7)$ were collected before NAT treatment initiation and at the indicated time intervals. Cells were stained with the respective antibodies and analyzed using flow cytometry. Lines connect the values of individual patients. ${ }^{*} P<0.05$; Wilcoxon signed-rank test. a Frequency of $\mathrm{CD}^{+}$and $\mathrm{CD} 8^{+} \mathrm{T}$ cells, CD $14^{+}$phagocytes, and CD $19^{+}$B cells within all peripheral blood mononuclear cells (PBMC). b Frequency of transitional (trans.) B cells, antigen-experienced (ag-exp.) B cells, memory B cells, and plasmablasts within all B cells. $\mathbf{c}$ The expression of activation markers and molecules involved in antigen presentation was determined after stimulation with $2 \mu \mathrm{g} / \mathrm{ml} \mathrm{CpG}$ for $20 \mathrm{~h}$. d PBMC were prestimulated for $12 \mathrm{~h}$ with $1 \mu \mathrm{g} / \mathrm{ml} \mathrm{CpG}$, followed by $4 \mathrm{~h}$ of $500 \mathrm{ng} / \mathrm{ml}$ ionomycin / $20 \mathrm{ng} / \mathrm{ml}$ phorbol 12-myristate 13-acetate stimulation. Cytokine production of $B$ cells $(\mathrm{BC})$ was quantified using the geometric mean fluorescent intensity (gMFI) of the respective cytokine

\section{Discussion}

In this manuscript, we aimed to investigate in a parallel approach how commonly used MS medications affect B cells, a procedure allowing us to compare treatment effects directly without inter-study discrepancies. Despite the fact that all investigated agents have proven efficacy in large clinical trials, our data showed that DMF, FTY, GA, and NAT exerted differential, in parts even opposing effects on the composition and properties of peripheral $\mathrm{B}$ cells. Confirming previous studies, our data showed that GA treatment has no detectable effect on B cell 


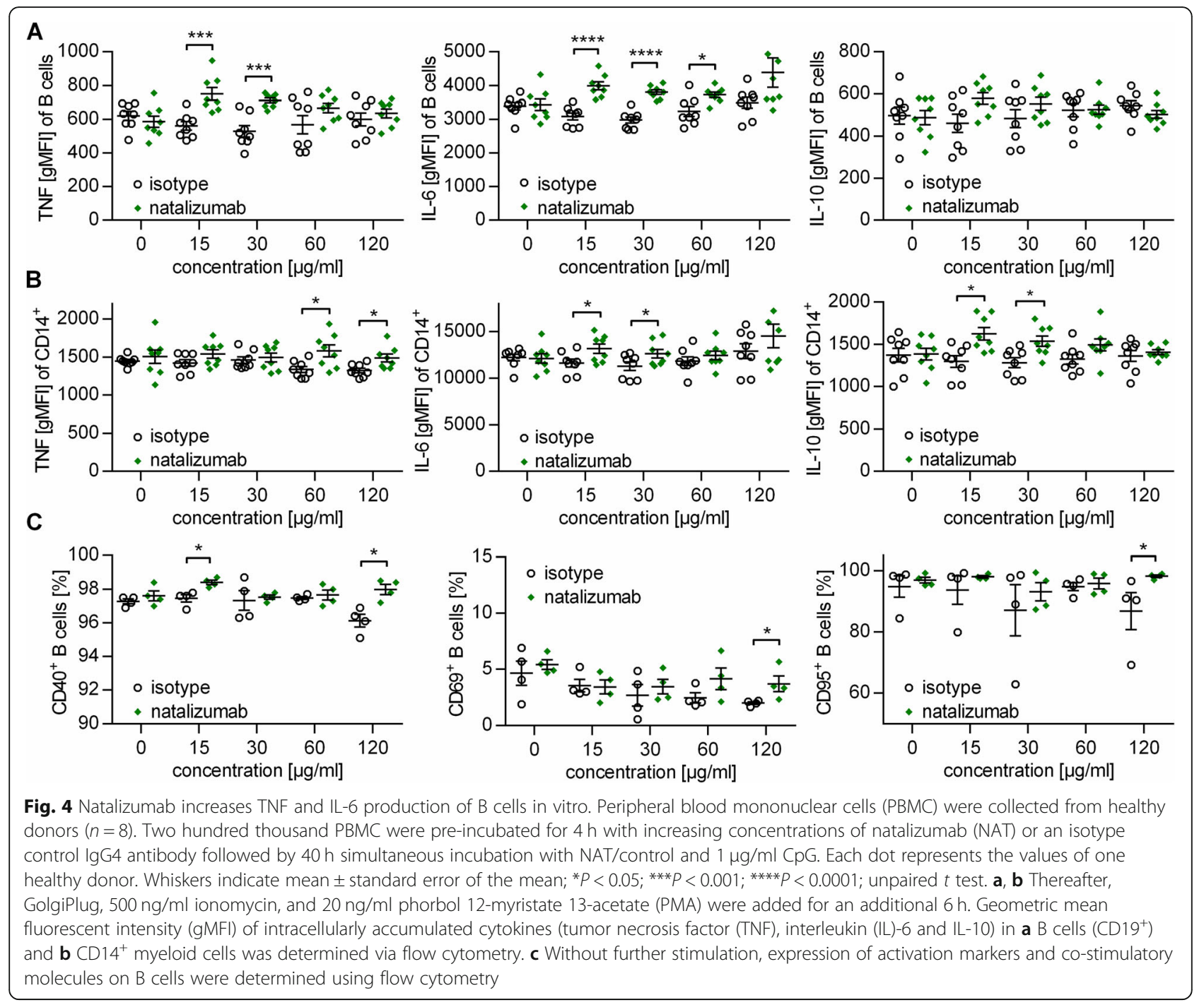

maturation and differentiation [5], while both DMF [6] and FTY [7] suppressed the prevalence and function of mature $\mathrm{B}$ cells and increased the relative frequency of their immature phenotypes.

NAT treatment on the contrary was associated with a substantial expansion of all leukocytes in blood, but most strikingly of mature B cell subsets. In an attempt to investigate whether this enrichment may ascribe to changes in cell survival, we challenged B cells in vitro with NAT, but detected neither effects on apoptosis nor proliferation. Various other explanations have been proposed to explain the rise of B cells in blood. Based on the observation that particularly the number of $\mathrm{CXCR}^{+} \mathrm{B}$ cells is increased in this compartment [8], Saraste et al. suggested that NAT treatment detains B cells with a high migratory capacity in the blood stream, which would-without treatment-extravasate into the inflamed tissue. Others though claimed that NAT treatment perturbs the homing of mature $\mathrm{B}$ cell subsets into secondary lymphoid organs, which increases their prevalence in the circulation [9]. Our in vitro observation that NAT exposure enhances neither apoptosis nor proliferation of B cells may add an additional explanation why B cells are enriched upon NAT treatment.

Besides these assumed effects on cellular compartmentalization, we observed that in vivo and in vitro treatment with NAT resulted in B cells with an elevated production of pro-, but not anti-inflammatory cytokines and enhanced expression of activation marker and co-stimulatory molecules. Especially the latter setting indicated that NAT exerted a direct stimulating effect on B cells, possibly mediated by the bidirectional signaling effect upon binding of the NAT to CD49d [10, $11]$, a mode of action suggested to increase IL-2, interferon- $\gamma$, and IL-17 production of purified $\mathrm{CD}_{4}^{+} \mathrm{T}$ cells in vitro [12]. In this context, it was shown that NAT therapy modulates microRNA and pro-inflammatory cytokine expression in $\mathrm{T}$ cells of MS patients $[13,14]$, 


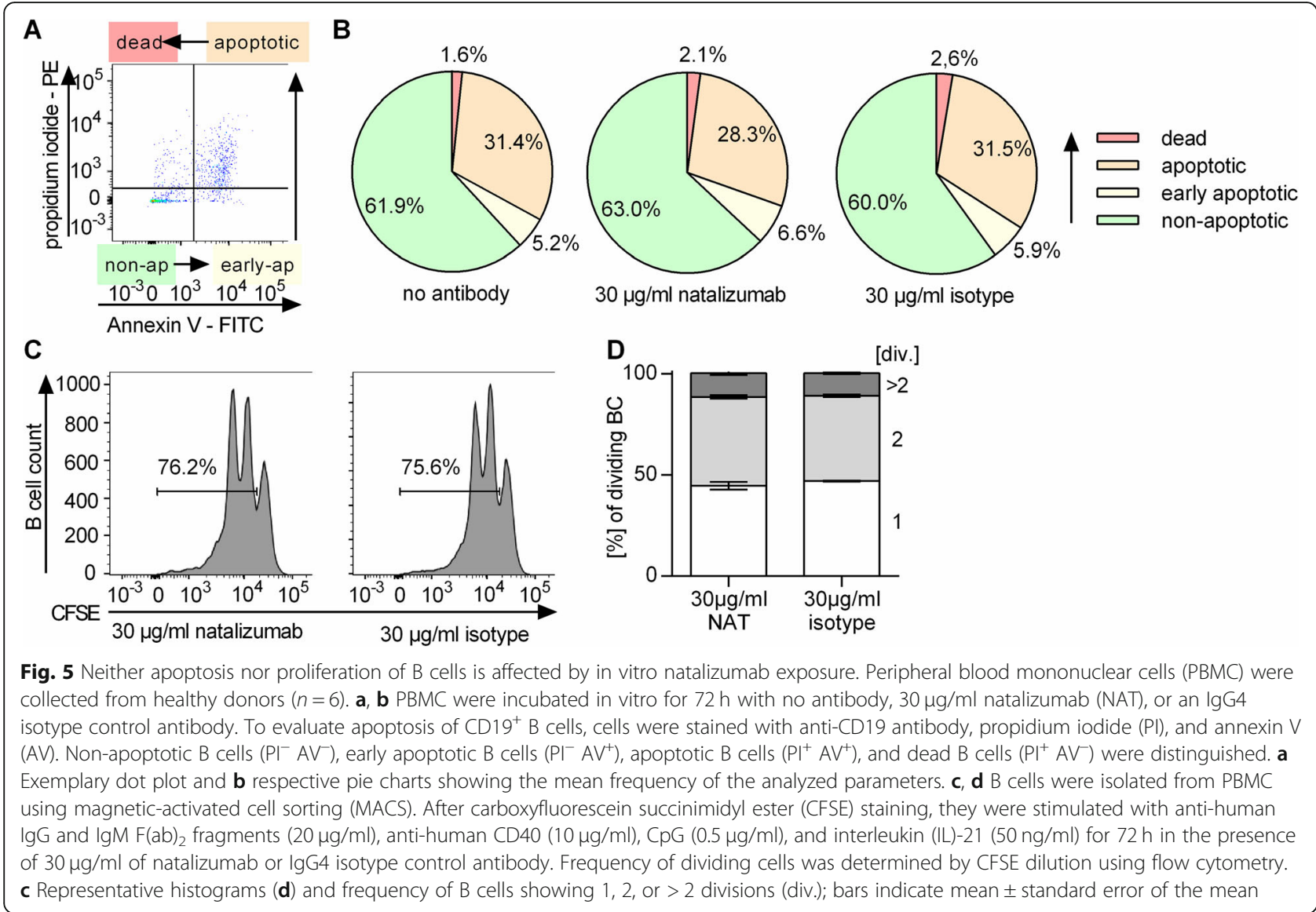

suggesting underlying epigenetic processes. In comparison with the described stimulating impact of NAT on $\mathrm{T}$ cells, we observed a much stronger effect on $\mathrm{B}$ cells in our study. This may be explained by the higher expression of CD49d on B cells than T cells [15]. Furthermore, CD49d is as well expressed on CD14 $4^{+}$myeloid cells [16], a fact possibly explaining why the production of pro-inflammatory cytokine by these cells is also enhanced upon NAT treatment.

We assume that the here described increase in B cell number and activation upon NAT treatment is not just an epiphenomenon but has clinical implications. This assumption is fueled by the observation that high $B$ cell frequencies after NAT treatment are associated with ongoing disease activity [17]. Along the same lines, a recent report showed that $B$ cells are enriched in the CNS parenchyma of patients experiencing relapses after NAT therapy cessation [18] placing focus on the question whether a prompt therapeutic follow-up with B cell suppressive agents can decrease the risk of such relapses. Indeed, first investigations showed that patients receiving the B cell-inhibiting agent FTY as follow-up treatment after NAT experience less frequent relapses than patients receiving GA [19] or no ensuing treatment [20]. B cell depletion with rituximab was even more effective than FTY as a post-NAT treatment [21], underscoring the presumed key role of B cells in relapses after NAT cessation.

Moreover, the development of extra nodal large B cell lymphomas that has been described in some NATtreated patients [22] may be linked to our observations regarding $\mathrm{B}$ cell activation and proliferation.

Lastly, the expansion of peripheral B cells with presumed pathogenic properties plausibly explains why NAT worsens neuromyelitis optica [23, 24]. In this regard, it needs to be evaluated how patients with other CNS demyelinating diseases, which show a prominent B cell contribution, such as myelin oligodendrocyte glycoprotein antibody-associated encephalomyelitis [25], or MS patients solely and consistently responding to plasmapheresis as relapse intervention [26] respond to NAT.

\section{Limitations}

We are aware that the small cohort size is limiting this study and that future investigations, which will include a larger population, extended clinical readouts, and a longer follow-up, should substantiate our data. More detailed in vitro experiments on isolated B cells may clarify if the observed pro-inflammatory effects are induced directly on B cells or indirectly via other immune cells. 


\section{Conclusions}

Established MS therapeutics exert fundamentally opposing effects on $\mathrm{B}$ cells, reaching from their inhibition (DMF, FTY) to substantial activation (NAT). Possible clinical consequences of these complex alterations yet need to be established.

\begin{abstract}
Abbreviations
CD: Cluster of differentiation; CFSE: Carboxyfluorescein succinimidyl ester; CNS: Central nervous system; CpG: CpG oligodeoxynucleotides; DME: Dulbecco's modified Eagle medium; DMF: Dimethyl fumarate; EDSS: Expanded disability status scale; FCS: Fetal calf serum; FTY: Fingolimod; GA: Glatiramer acetate; gMFI: Geometric mean fluorescent intensity; HLADR: Human leukocyte antigen - DR isotype; IgG: Immunoglobulin G; IL: Interleukin; LPS: Lipopolysaccharides; MACS: Magnetic-activated cell sorting; MHC-II: Major histocompatibility complex class 2; MS: Multiple sclerosis; NAT: Natalizumab; PBMC: Peripheral blood mononuclear cells; PMA: Phorbol 12-myristate 13-acetate; TNF: Tumor necrosis factor
\end{abstract}

\section{Acknowledgements}

We thank Julian Koch for the excellent technical support.

\section{Authors' contributions}

MSW and SHK conceived and directed the project. HLP and LH collected blood samples from all patients included in the study. JWT, HLP, IS, and CR carried out experiments and the interpreted results. JWT and SHK wrote the manuscript. KG carried out the experiments. MSW, WB, SHK, and LH contributed to the interpretation of results and provided feedback on the manuscript. All authors gave final approval for the submitted version.

\section{Funding}

Jan W. Traub and Christoph Rowold are supported by the VorSPrUNG program of the Department of Neurology at the Universitätsmedizin Göttingen. Silke Häusser-Kinzel is supported by the Startprogramm of the Universitätsmedizin Göttingen. Leila Husseini receives research support from Novartis. Martin S. Weber is serving as an editor for PLoS One. He receives research support from the National Multiple Sclerosis Society (NMSS; PP 1660), the Deutsche Forschungsgemeinschaft (DFG; WE 3547/5-1), from Novartis, TEVA, Biogen-Idec, Roche, Merck, and the ProFutura Programm of the Universitätsmedizin Göttingen.

\section{Availability of data and materials}

The data that support the findings of this study are available from the corresponding author upon reasonable request.

\section{Ethics approval and consent to participate}

Relapsing-remitting MS patients were enrolled after written informed consent; protocols were approved by the ethical review committee of the University Medical Center Göttingen (\#3/4/14).

\section{Consent for publication}

Not applicable.

\section{Competing interests}

The authors declare that they have no competing interests.

\section{Author details}

${ }^{1}$ Institute of Neuropathology, University Medical Center, Robert-Koch-Straße 40, 37099 Göttingen, Germany. ²Department of Neurology, University Medical Center, Robert-Koch-Straße 40, 37099 Göttingen, Germany. ${ }^{3}$ Institute of Clinical Neuroimmunology, Ludwig Maximilian University, Großhaderner Straße 9, 82152 Munich, Germany.

Received: 29 May 2019 Accepted: 23 September 2019 Published online: 16 November 2019

\section{References}

1. Hauser SL, Bar-Or A, Comi G, et al. Ocrelizumab versus interferon beta-1a in relapsing multiple sclerosis. N Engl J Med. 2017;376(3):221-34.
2. Bar-Or A, Fawaz L, Fan B, et al. Abnormal B-cell cytokine responses a trigger of T-cell-mediated disease in MS? Ann Neurol. 2010;67(4):452-61.

3. Montalban X, Gold R, Thompson AJ, et al. ECTRIMS/EAN Guideline on the pharmacological treatment of people with multiple sclerosis. Mult Scler. 2018;24(2):96-120.

4. van Kempen $\mathrm{ZL}$, Leurs $\mathrm{CE}$, Witte $\mathrm{Bl}$, et al. The majority of natalizumabtreated MS patients have high natalizumab concentrations at time of redosing. Mult Scler. 2018;24(6):805-10.

5. Ireland SJ, Guzman AA, O'Brien DE, et al. The effect of glatiramer acetate therapy on functional properties of B cells from patients with relapsingremitting multiple sclerosis. JAMA Neurol. 2014;71(11):1421-8.

6. Traub J, Traffehn S, Ochs J, et al. Dimethyl fumarate impairs differentiated B cells and fosters central nervous system integrity in treatment of multiple sclerosis. Brain Pathol. 2019;29(5):640-57.

7. Blumenfeld S, Staun-Ram E, Miller A. Fingolimod therapy modulates circulating $B$ cell composition, increases $B$ regulatory subsets and production of IL-10 and TGFbeta in patients with multiple sclerosis. J Autoimmun. 2016;70:40-51.

8. Saraste M, Penttila TL, Airas L. Natalizumab treatment leads to an increase in circulating CXCR3-expressing B cells. Neurol Neuroimmunol Neuroinflamm. 2016;3(6):e292.

9. Planas R, Jelcic I, Schippling S, Martin R, Sospedra M. Natalizumab treatment perturbs memory- and marginal zone-like B-cell homing in secondary lymphoid organs in multiple sclerosis. Eur J Immunol. 2012; 42(3):790-8

10. Hynes RO. Integrins: bidirectional, allosteric signaling machines. Cell. 2002; 110(6):673-87

11. Hausler D, Nessler S, Kruse N, Bruck W, Metz I. Natalizumab analogon therapy is effective in a B cell-dependent multiple sclerosis model. Neuropathol Appl Neurobiol. 2015;41(6):814-31.

12. Benkert TF, Dietz L, Hartmann EM, et al. Natalizumab exerts direct signaling capacity and supports a pro-inflammatory phenotype in some patients with multiple sclerosis. PLoS One. 2012;7(12):e52208.

13. Ingwersen J, Menge $T$, Wingerath $B$, et al. Natalizumab restores aberrant miRNA expression profile in multiple sclerosis and reveals a critical role for miR-20b. Ann Clin Transl Neurol. 2015;2(1):43-55.

14. Mameli G, Arru G, Caggiu E, et al. Natalizumab therapy modulates miR-155, miR-26a and proinflammatory cytokine expression in MS patients. PLoS One. 2016;11(6):e0157153.

15. Niino M, Bodner $C$, Simard ML, et al. Natalizumab effects on immune cell responses in multiple sclerosis. Ann Neurol. 2006;59(5):748-54.

16. Ammon C, Meyer SP, Schwarzfischer L, Krause SW, Andreesen R, Kreutz M. Comparative analysis of integrin expression on monocyte-derived macrophages and monocyte-derived dendritic cells. Immunology. 2000; 100(3):364-9.

17. Villar LM, Garcia-Sanchez MI, Costa-Frossard L, et al. Immunological markers of optimal response to natalizumab in multiple sclerosis. Arch Neurol. 2012; 69(2):191-7.

18. Larochelle C, Metz I, Lecuyer MA, et al. Immunological and pathological characterization of fatal rebound MS activity following natalizumab withdrawal. Mult Scler. 2017;23(1):72-81.

19. laffaldano P, Lucisano G, Pozzilli C, et al. Fingolimod versus interferon beta/ glatiramer acetate after natalizumab suspension in multiple sclerosis. Brain. 2015;138(Pt 11):3275-86.

20. Sangalli F, Moiola L, Ferre $L$, et al. Long-term management of natalizumab discontinuation in a large monocentric cohort of multiple sclerosis patients. Mult Scler Relat Disord. 2014;3(4):520-6.

21. Alping P, Frisell $T$, Novakova $L$, et al. Rituximab versus fingolimod after natalizumab in multiple sclerosis patients. Ann Neurol. 2016;79(6):950-8.

22. Law JY, Kim DW, Sturgis A, Naina HV. Non-Hodgkin lymphoma of the stomach in a patient treated with natalizumab. Clin Med Insights Oncol. 2015;9:61-3.

23. Kleiter I, Hellwig K, Berthele A, et al. Failure of natalizumab to prevent relapses in neuromyelitis optica. Arch Neurol. 2012;69(2):239-45.

24. Kitley J, Evangelou N, Kuker W, Jacob A, Leite MI, Palace J. Catastrophic brain relapse in seronegative NMO after a single dose of natalizumab. J Neurol Sci. 2014;339(1-2):223-5.

25. Weber MS, Derfuss T, Bruck W. Anti-myelin oligodendrocyte glycoprotein antibody-associated central nervous system demyelination-a novel disease entity? JAMA Neurol. 2018;75(8):909-10. 
26. Stork $L$, Ellenberger $D$, Beissbarth $T$, et al. Differences in the reponses to apheresis therapy of patients with 3 histopathologically classified immunopathological patterns of multiple sclerosis. JAMA Neurol. 2018;75(4): $428-35$.

\section{Publisher's Note}

Springer Nature remains neutral with regard to jurisdictional claims in published maps and institutional affiliations.

Ready to submit your research? Choose BMC and benefit from:

- fast, convenient online submission

- thorough peer review by experienced researchers in your field

- rapid publication on acceptance

- support for research data, including large and complex data types

- gold Open Access which fosters wider collaboration and increased citations

- maximum visibility for your research: over $100 \mathrm{M}$ website views per year

At $\mathrm{BMC}$, research is always in progress.

Learn more biomedcentral.com/submissions 